\title{
Bradycardia-dependent interatrial block with retrograde left atrial activation
}

\author{
José A. Sobrino, Alejandro del Rio, Isabel Maté, and Nicolás Sobrino \\ From the Cardiovascular Surgery Department, Cardiology Unit, La Paz Hospital, Madrid, Spain
}

$A$ patient with a peculiar interatrial block is reported. The electrocardiogram showed a short PR interval and negative $P$ waves in II, III, and aVF, which were preceded, 0.07 s earlier, by another positive $P$ wave present in the right praecordial leads which were absent in the limb leads.

From the study with His bundle electrograms, high right atrial electrograms, and bipolar oesophageal electrocardiograms, it could be proved that atrioventricular, His-Purkinje, and right intra-atrial conduction were normal, and that $P$ waves recorded in limb leads represented left atrial depolarization; whereas the ones in the right praecordial leads corresponded to right atrial activation.

The vectorial analysis from both $P$ waves and atrial potentials showed that the left atrium was activated in a retrograde fashion, because of an interatrial block. This block was bradycardia dependent and it disappeared in the cycles shorter than $800 \mathrm{~ms}$.

Interatrial block is an electrocardiographic entity whose features are dependent upon its severity, ranging from an abnormal widening of the $P$ waves (Bekheit et al., 1972), to the existence of two $\mathrm{P}$ waves with different rates, reflecting an independent pacemaker for each atrium, one of them being the main pacemaker of the heart (Cohen and Scherf, 1965).

At present, there are two theories to explain the activation of the atria: Lewis (1925) thought it was a sequential and circumferential process; later it was considered that the activation process occurred through specialized pathways (Wenkebach, 1907; Thorel, 1910; Bachmann, 1916; James, 1963). In accordance with the latter theory, the injury of the specialized pathways would produce intra-atrial and interatrial blocks of different types, the injuries to Bachmann's bundle would be the commonest explanation for the delay in the impulse reaching the left atrium.

A patient is reported with an interatrial block in which the left atrium was activated retrogradely from the lower aspects of the right atrium, with a considerable delay.

\section{Case history}

A 67-year-old man complained of dizziness and mental torpor, occurring three months before his admittance to hospital. He described a past history of palpitations but his basal pulse rate was between 35 and 60 beats/min. Physical examination, chest $x$-ray examination, and standard laboratory tests were normal. Several electrocardiograms showed nodal rhythm, sometimes with very slow rate. The diagnosis of 'sick sinus syndrome' was made and the patient sent to La Paz Hospital.

Surface electrocardiograms, bipolar oesophageal electrocardiogram, bipolar high right atrial electrograms, and His bundle electrograms were performed. Because of technical problems during the His bundle electrogram study it was impossible to perform atrial pacing. As the patient continued with frequent spells of dizziness, a ventricular demand pacemaker was implanted.

\section{Electrocardiogram}

The $\mathbf{P}$ waves in the basal electrocardiogram were: negative in II, III, aVF; positive in V1, V2, and V3; biphasic (+ - ) in V4 and V5; and flattened in I and V6. The QRS complex, $T$ waves, and ST segment were normal. The PR interval in lead III measured $0.08 \mathrm{~s}$ and in V1 $0.14 \mathrm{~s}$. Simultaneous recordings of leads I, II, III, and V1 showed that the $P$ wave in right praecordial leads $(P p)$ preceded the $P$ wave in standard leads (Ps) by $0.06-0.08 \mathrm{~s}$. When PP intervals shortened, Ps changed to positive and $\mathrm{Pp}$ and $\mathrm{Ps}$ began simultaneously (Fig. 1A and 1B). 
His bundle electrogram and high right atrium The His bundle electrogram was recorded using the technique described by Scherlag et al. (1969), a tripolar catheter with an interelectrode distance of $10 \mathrm{~mm}$, connected to a junction box (keyboard switch box-Siemens Elema), connected in turn to an Elema Schonander Mingograph 81 recorder. The tracing was recorded at $100 \mathrm{~mm} / \mathrm{s}$. The high right atrial electrogram was obtained with the same catheter, placing the tip in the lateral and superior aspects of the right atrium.

High right atrial recordings showed that the beginning of Ps in lead III was preceded by the atrial potential (A) by $75 \mathrm{~ms}$. The interval between $A$ and the end of Ps measured $120 \mathrm{~ms}$. The interval between the end of $P s$ and $Q$ wave was $25 \mathrm{~ms}$. When the AA cycles measured $800 \mathrm{~ms}$ or less, Ps polarity changed from negative to positive, and $A$ was recorded $10 \mathrm{~ms}$, before onset of the $P$ wave. The interval between $A$ and the end of $P$ wave was $80 \mathrm{~ms}$, and the interval between the end of the $P$ wave and the $Q$ was $60 \mathrm{~ms}$ (Fig. 2A).

In the His bundle electrogram, the $\mathrm{AH}$ interval measured $90 \mathrm{~ms}$, and the $\mathrm{HV} 50 \mathrm{~ms}$. When the AA interval shortened, the AH lengthened slightly, while the HV did not change. The interval between low right atrial potential and Ps wave was $70 \mathrm{~ms}$ in the longer cycles (Fig. 2B).

\section{Bipolar oesophageal electrogram}

During recording, though ventricular premature beats appeared, the negative $P$ waves of the supraventricular complexes in leads II, III, and aVF coincided with the positive potential in the electrogram.

\section{Discussion}

The standard electrocardiogram can be inadequate in many cases when used as the sole means to study the place where the $P$ waves originate, and

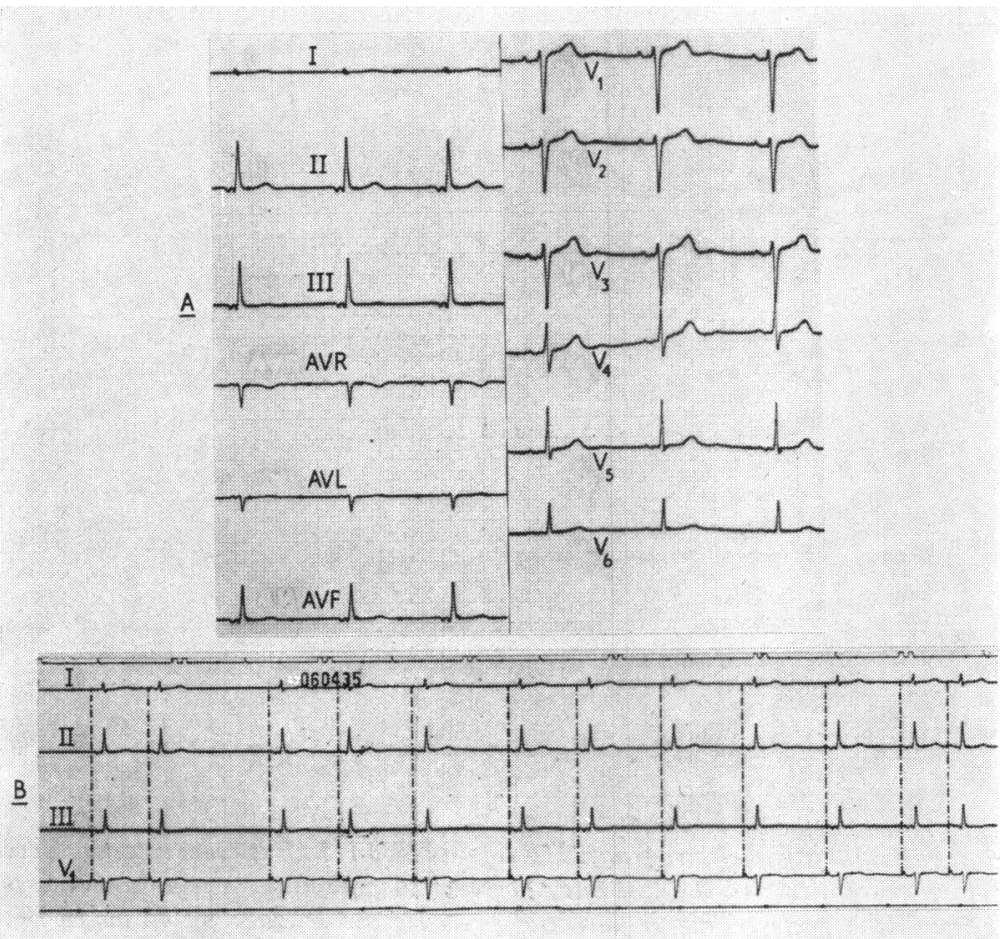

FIG. 1 (A) Electrocardiogram showing basal rhythm (see text). (B) Electrocardiogram showing simultaneous recordings of leads $I, I I, I I I$, and V1. The $P$ wave in V1 precedes the $P$ wave in limb leads by 0.06 to $0.08 \mathrm{~s}$, when PP cycles range between 1600 and $960 \mathrm{~ms}$. In the second and last beats with preceding $P P$ cycles of 800 and $620 \mathrm{~ms}$ the $P$ wave in limb leads in positive and simultaneous with the $P$ wave in V1. The $P$ wave is flat in $I, I I$, and III in beat 4, with a PP cycle of $920 \mathrm{~ms}$ (paper speed $24 \mathrm{~mm} / \mathrm{s}$ ). 
more sophisticated studies will be needed. In our case, the standard electrocardiogram led us to suggest the existence of a nodal rhythm. However, in a retrospective electrocardiographic study performed after His bundle electrograms, it was clear that the $\mathbf{P}$ waves in limb leads were preceded by another $\mathbf{P}$ wave only recorded in praecordial leads.

The negative $P$ waves in II, III, and aVF (Ps) represented left atrial activation resulting from the following facts: in the basal rhythm the Ps coincided with the atrial potentials in bipolar oesophageal electrogram, and were preceded by $75 \mathrm{~ms}$ by the right intra-atrial potentials. On the other hand, the positive $\mathbf{P}$ waves in the right praecordial leads $(\mathrm{Pp})$ preceded the $\mathrm{Ps}$ by $0.06-0.08 \mathrm{~s}$ and, therefore, the $\mathrm{Pp}$ should correspond to the $\mathrm{A}$ potential in the high right atrium or His bundle electrogram. The axis of $\mathrm{Ps}$ wave $\left(\hat{\mathrm{a} P}=-90^{\circ}\right)$, the positive deflections in the bipolar electrogram, and the short $P R$, pointed to a left atrial activation occurring from below, and a right atrial activation mainly forward ( $\mathrm{Pp}$ was positive in leads V1 and V2 and not evident in the limb leads). The atrioventricular node and left atrial activation originated from the right atrial pacemaker because all the $\mathrm{H}$ potentials and Ps waves were preceded by $A$ potentials, and when the rate increased, the $\mathrm{AH}$ lengthened.

The right atrial activation could originate in the sinus node or in a high right atrial pacemaker, but could not result from a nodal or low atrial rhythm, since $\mathrm{AH}$ was not short and in nodal or low atrial rhythms the activation of both atria must be simultaneous (Massumi et al., 1969).

Waldo et al. (1971), after producing a selective lesion in Bachmann's bundle in dogs, obtained wide, flat $P$ waves with a negative second half in limb leads, very similar to the ones found in our patient. Retrograde left atrial activation probably was made from a low interatrial pathway. Scherlag, Yeh, and Robinson (1972) have proved, in dogs, the existence of this pathway, joining the inferior aspects of the right atrium and left atrium.

The changes in Ps polarity, returning to normal when AA cycles shortened, could be produced by an atrial focus, different from the one responsible for the basal rhythm. However, as all the A deflec-

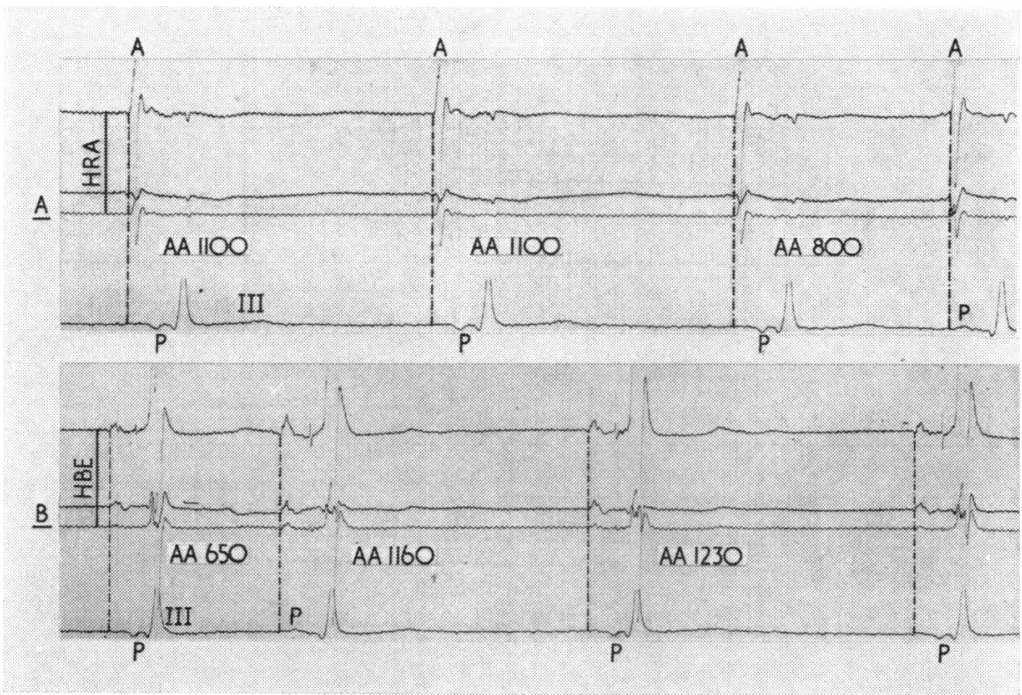

FI G. 2( $A$ ) High right atrial electrogram (HRA) and lead III :P wave is negative in the first three beats and turns to positive in the last one; however $A$ potential has the same morphology and amplitude in all the cycles. This $A$ potential precedes the $P$ wave by $75 \mathrm{~ms}$ in the first three cycles, and by $10 \mathrm{~ms}$ in the last cycle. In the latter the preceding $A A$ interval is shorter (paper speed $100 \mathrm{~mm} / \mathrm{s}$ ). (B) His bundle electrogram (HBE) and lead III : beats 1, 3, and 4 with long $A A$ cycles, show negative $P$ waves, an $A H$ interval of $90 \mathrm{~ms}$, and $H V$ interval of $50 \mathrm{~ms}$. The low atrial potential $(A)$ precedes the $P$ wave by 70 msec. In beat 2 with a preceding $A A$ cycle of $650 \mathrm{~ms}$, an $A H$ interval of $110 \mathrm{~ms}$ and an $H V$ interval of $50 \mathrm{~ms}$, the A potential is simultaneous with the theoretical onset of the $P$ wave which becomes positive (paper speed $100 \mathrm{~mm} / \mathrm{s}$ ). 
tions had the same shape and amplitude, they probably originated in the same pacemaker or one close by. On the other hand, even if there were two right atrial foci, the differences in width and shape of the $\mathbf{P}$ wave could not exist with an intact interatrial conduction system (Waldo et al., 1970, 1971) and so the obvious changes in the $P$ wave have to be ascribed to an intermittent interatrial block related to the heart rate.

There are several reports proving the existence of bradycardia-dependent bundle-branch block. The mechanism of this type of block has been related to the phase 4 (Rosenbaum et al., 1973). Though bradycardia-dependent interatrial blocks have not been reported, Childers, Merideth, and Moe (1968) showed, in dogs, the existence of a supernormal conduction phase in Bachmann's bundle, and Agha et al. (1972) proved the existence of a supernormal intra-atrial and interatrial conduction in 5 patients by atrial pacing with a cycle length of 500 to $600 \mathrm{~ms}$. In our case the disappearance of the interatrial block with $\mathrm{AA}$ cycles of $800 \mathrm{~ms}$ or less, and its presence in the basal rhythm with longer AA intervals, suggest the existence of a bradycardia-dependent Bachmann's bundle block. This was probably related to the phase 4 of the depolarization, even though the presence of phase-4 in Bachmann's bundle has not been shown yet.

As well as the electrophysiological data, we think that this report has clinical implications because of the possibility that some cases thought to be nodal rhythms in the electrocardiogram might correspond to interatrial block with retrograde left atrial activation.

We wish to thank Martin L. Schwartz for his assistance.

\section{References}

Agha, A. S., Castillo, C. A., Castellanos, A., Jr., Myerburg, R. J., and Tessler, M. P. (1972). Supernormal conduction in the human atria. Circulation, 46, 522.
Bachmann, G. (1916). The inter-auricular time interval. American fournal of Physiology, 41, 309.

Bekheit, S., Murtagh, G., Morton, P., and Fletcher, E. (1972). His bundle electrogram in $\mathrm{P}$ mitrale. British Heart Fournal, 34, 1057.

Childers, R. W., Merideth, J., and Moe, G. K. (1968). Supernormality in Bachmann's bundle. An in vitro and in vivo study in the dog. Circulation Research, 22, 363.

Cohen, J., and Scherf, D. (1965). Complete interatrial and intra-atrial block (atrial dissociation). American Heart fournal, 70, 23.

James, T. N. (1963). The connecting pathways between the sinus node and A-V node and between the right and left atrium in the human heart. American Heart fournal, 66, 498.

Lewis, T. (1925). The Mechanism and Graphic Registration of the Heart Beat, 3rd ed., pp. 83-88. Shaw, London.

Massumi, R. A., Sari, R. K., Tawakkol, A. A., Rios, J. C., and Jackson, H. (1969). Time sequence of right and left atrial depolarization as a guide to the origin of the $P$ waves. American Fournal of Cardiology, 24, 28.

Rosenbaum, M. B., Elizari, M. V., Lázzari, J. O., Halpern, M. S., Nau, G. J., and Levi, R. J. (1973). The mechanism of intermittent bundle branch block: relationship to prolonged recovery, hypopolarization and spontaneous diastolic depolarization. Chest, 63, 666.

Scherlag, B. J., Lau, S. H., Helfant, R. H., Berkowitz, W. D., Stein, E., and Damato, A. N. (1969). Catheter technique for recording His bundle activity in man. Circulation, $39,13$.

Scherlag, B. J., Yeh, B. K., and Robinson, M. J. (1972). Inferior interatrial pathway in the dog. Circulation Research, 31, 18.

Thorel, C. (1910). Über den Aufbau des Sinusknotens und seine Verbindung mit der Cava superior und den Wenckebachschen Bündeln. Münchener medizinische Wochenschrift, 57, 183.

Waldo, A. L., Bush, H. L., Jr., Gelband, H., Zorn, G. L., Jr., Vitikainen, K. J., and Hoffman, B. F. (1971). Effects on the canine $\mathbf{P}$ wave of discrete lesions in the specialized atrial tracts. Circulation Research, 29, 452.

Waldo, A. L., Vitikainen, K. J., Kaiser, G. A., Malm, J. R., and Hoffman, B. F. (1970). The $P$ wave and P-R interval: effects of the site of origin of atrial depolarization. Circulation, 42, 653.

Wenckebach, K. F. (1907). Beiträge zur Kenntnis der menschlichen Herztätigkeit. II. Archiv für Physiologie, 31, 1 .

Requests for reprints to Dr. José A. Sobrino, Hilarion Eslava-55, Madrid-15, Spain. 